\title{
Clinical utility of RASSF1A methylation in human malignancies
}

\author{
A M Grawenda ${ }^{1}$ and E O’Neill ${ }^{*}$ \\ ${ }^{1}$ CRUK/MRC Oxford Institute, Department of Oncology, University of Oxford, Oxford, UK
}

The high frequency of RASSF1A methylation has been noted in a vast number of patients in a broad spectrum of malignancies, suggesting that RASSF1A inactivation is associated with cancer pathogenesis. However, whether this recurrent incidence of RASSF1A hypermethylation in human malignancies and its association with more aggressive tumour phenotype is a frequent event across different cancer types has not yet been discussed. In this review, we interrogated existing evidence for association of RASSF1A hypermethylation with clinicopathological characteristics that can indicate more invasive lesions.

One of the greatest challenges facing modern oncology is the development of biomarkers that will improve prognostication as well as prediction for the use of targeted therapies. Adequate biomarkers that define the molecular complexity of cancer could improve both diagnosis and treatment, leading to significant advances in cancer patient care. It has long been envisioned that such biomarkers will help distinguish between indolent and aggressive cancers which, in an advent of improved cancer screening, will become increasingly important with greater success in identification of earlier low-grade tumours. Molecular biomarkers that enable the sensing of malignant transformation and cancer progression will undoubtedly have strong potential as prognostic biomarkers and could lead to improvements in cancer screening and management strategies for cancer patients. However, surprisingly few such biomarkers are currently available or are in development following solid clinical confirmation. Here we review the clinical evidence for one strong emerging candidate biomarker, RASSF1A, that has been implicated across all major solid tumours as a prognostic marker for poor survival and is showing signs of predictive power to certain treatments (Hesson et al, 2007). Interestingly, given the current concentration on screening of patients for genomic mutations, this is an epigenetic event indicating the potential for more comprehensive analysis of patient material in providing biomarker delivery.

RASSF $1 A$ is one of the most frequently epigenetically inactivated tumour-suppressor genes in sporadic human malignancies (Donninger et al, 2007; Hesson et al, 2007; Van der Weyden and Adams, 2007). As a component of key cancer pathways, namely Ras/ PI3K/AKT, Ras/RAF/MEK/ERK and Hippo pathways, inactivation of RASSF1A is an important factor contributing to pathogenesis and progression of solid tumours (Guo et al, 2007; Van der Weyden and Adams, 2007). Originally discovered in the search for a tumour suppressor on chromosome $3 \mathrm{p} 21$, subsequent analysis found that epigenetic inactivation of the RASSF1 promoter region by DNA methylation was more widespread in lung cancer than loss of heterozygosity (Kok et al, 1987; Dammann et al, 2000). Methylation of the RASSF1A gene is rare in normal tissues, whereas the frequency of methyl-cytosine in the promoter spanning CpG island increases in tumour tissue and is one of the highest described, leading to multiple correlations of the biomarker with increased risk of lung cancer (Donninger et al, 2007).

High frequencies of RASSF1A promoter 'hypermethylation' have subsequently been reported in a number of different malignancies. RASSF1A hypermethylation frequency ranges up to $99 \%$ in tumours compared with $0 \%$ in normal surrounding tissue, with the highest frequencies of up to 88,95 and $99 \%$ being reported in lung, breast and prostate cancers, respectively (reviewed in Donninger et al, 2007). The high frequency of RASSF1A promoter methylation has also been associated with cancer pathogenesis and more aggressive clinical phenotype. Additionally, a number of studies have successfully demonstrated that RASSF1A methylation status can be derived from cell-free circulating tumour DNA (ctDNA; Wang et al, 2007; Chan et al, 2008; Göbel et al, 2011; Ponomaryova et al, 2013). ctDNA offers an alternative diagnostic material for clinical use as it is more readily accessible for analysis than tumour material. Together, RASSF1A methylation status holds a strong potential for clinical utility as an attractive biomarker for cancer risk and prognosis.

For the purpose of this review, we selected studies with cohort sizes of $\geqslant 50$ patients which reported any clinicopathological 
features associated with RASSF1A methylation. We categorised different clinicopathological features such as (i) cancer risk (assessed in case-control studies only), (ii) advanced stage and/or grade, (iii) local recurrence or distal metastasis, (iv) poor overall survival and (v) poor disease-free survival. Up until December 2014, 76 studies in 11 different cancer types, inclusive of 8 meta-analyses, reported clinical significance of RASSF1A promoter hypermethylation (Table 1).

\section{BREAST CANCER}

A total of 8 individual reports and 1 meta-analysis of 1759 breast cancer patients lend strong support to RASSF1A promoter hypermethylation involvement in the tumourogenesis of breast cancer (Shinozaki et al, 2005; Bagadi et al, 2008; Euhus et al, 2008; Karray-Chouayekh et al, 2010; Buhmeida et al, 2011; Göbel et al, 2011; Jiang et al, 2012; Wang et al, 2012; Xu et al, 2012; Stuopelytė et al, 2013; Hagrass et al, 2014). The study of tumour-suppressor gene methylation frequency, including RASSF $1 A$, in benign and malignant tissues of 69 breast cancer patients and breast tissues of 95 unaffected women by Euhus et al (2008), demonstrated that promoter methylation of RASSF1A is the most frequent among all tumour-suppressor genes tested and correlates with increased breast cancer risk (odds ratio (OR) 5.28), indicating that assessment of RASSF1A promoter methylation in benign tissues could improve breast cancer risk stratification.

Metastasis is a primary cause of death in around $90 \%$ of cancer patients (Mehlen and Puisieux, 2006), therefore it is of great importance to identify clinically relevant biomarkers that can identify groups of patients with high risk of metastatic disease. Strikingly, RASSF1A hypermethylation is strongly associated with poor prognosis and adverse cancer outcome in 7 individual studies and one meta-analysis of 1795 cases. Specifically, breast tumours with inactivated RASSF1A associated with advanced stage (KarrayChouayekh et al, 2010; Hagrass et al, 2014), lymph node metastasis (Bagadi et al, 2008; Hagrass et al, 2014), higher risk of recurrence (Jiang et al, 2012), shorter progression-free survival (Buhmeida et al, 2011; Göbel et al, 2011; Xu et al, 2012) and poor overall survival (Karray-Chouayekh et al, 2010; Göbel et al, 2011; Jiang et al, 2012; Wang et al, 2012; Xu et al, 2012). Together, this evidence strongly suggests that epigenetic inactivation of the RASSF1A gene is a critical event in progression of breast cancer and that RASSF1A promoter methylation could serve as a biomarker for more aggressive breast tumours with high risk of metastasis. Additionally, evidence exists suggesting that RASSF1A methylation could be utilised in the clinic for monitoring response to adjuvant therapy, whereby depletion of RASSF1A methylation in ctDNA has been associated with good response to adjuvant regimens (Fiegl et al, 2005; Avraham et al, 2012).

Oestrogen receptor (ER) status is one of the most important prognostication factors in breast cancer, whereby ER-positive tumours are considered less aggressive (Reis-Filho and Pusztai, 2011). Interestingly, a study of 193 breast cancer patients by $\mathrm{Xu}$ et al (2012), which reported association of RASSF1A methylation with poor progression-free and overall survival, demonstrated that higher median RASSF1A methylation was observed in ER- and progesterone receptor (PR)-positive tumours. Similarly, in a study of 72 breast cancer patients Stuopelyte et al (2013) reported that RASSF1A methylation is more frequent in less aggressive, ERpositive tumours of low grade and with low proliferative potential. The prevalence of RASSF1A hypermethylation in hormone receptor-positive tumours was also reported in relatively larger breast cancer studies of 151 and 765 patients (Shinozaki et al, 2005; Cho et al, 2012); however, no clinical associations that would indicate more aggressive phenotype in tumours with hypermethylated RASSF1A were found in these patient cohorts. Inactivation of RASSF1A and its association with more aggressive phenotype is not restricted to hormone receptor-positive breast tumours. In a study of 120 patients, Hagrass et al (2014) reported that RASSF1A methylation associates with invasive carcinoma, advanced stage and lymph node metastasis in ER-, PR- and HER2negative breast tumours. Therefore, further investigation in much larger patient cohorts is needed to better understand the possible interaction of RASSF1A inactivation with hormone receptor status and prognosis.

Taken together, the body of evidence gives strong support to the hypothesis that inactivation of RASSF1A in breast tumours leads to more aggressive phenotype, likely independent of hormone receptor status, and it can be speculated that RASFF1A hypermethylation could identify a subgroup of ER-positive breast cancer patients with more aggressive tumours with a high risk of metastasis.

\section{LUNG CANCER}

Apparent correlation of RASSF1A methylation with clinical characteristics of invasive tumours is also evident in lung cancer (Table 1). Association of high levels of RASSF1A promoter methylation with cancer risk has been demonstrated in two independent clinical studies (Hsu et al, 2007; Li et al, 2012) and one meta-analysis of 2008 cases (Huang et al, 2014). RASSF1A methylation associates with elevated risk of lung cancer with reported OR ranging from 7.5, in a study of 56 lung cancer cases and 52 healthy controls, through OR 9.9 in a study of 63 non-small cell lung patients and 36 controls, to OR 16.2 reported in a meta-analysis of 2008 cases and 1239 controls (Hsu et al, 2007; Li et al, 2012; Huang et al, 2014).

Lung tumours with hypermethylated RASSF1A methylation are poorly differentiated (Tomizawa et al, 2002; Wang et al, 2007) and associate with advanced stage (Wang et al, 2007; Lee et al, 2012) and local recurrence (Tomizawa et al, 2002; Endoh et al, 2003; Kubo et al, 2009; Buckingham et al, 2010). Similarly to breast cancer, a strong body of evidence supports an association of RASSF1A hypermethylation with adverse outcome of lung cancer, whereby 8 independent studies (Burbee et al, 2001; Kim et al, 2003a, 2003b; Wang et al, 2004; Fischer et al, 2007; Yanagawa et al, 2007; De Fraipont et al, 2012) and a meta-analysis of a total of 2802 lung cancer patients (Wang et al, 2011) demonstrate significantly shorter overall survival in those patients whose tumours had inactivated RASSF1A by promoter methylation. Additionally, poor progression-free survival of patients with hypermethylated RASSF1A was demonstrated in two independent studies of non-small cell lung cancer patients (De Fraipont et al, 2012; Ko et al, 2013).

Although some studies included more aggressive small cell lung carcinomas (Wang et al, 2007; Kubo et al, 2009), the majority of reports were wholly conducted in non-small cell lung carcinoma (NSCLC) specimens (Burbee et al, 2001; Tomizawa et al, 2002; Endoh et al, 2003; Kim et al, 2003a, 2003b; Wang et al, 2004, 2011; Yanagawa et al, 2007; Buckingham et al, 2010; Ko et al, 2013). Therefore, it could be speculated that RASSF1A methylation may be a good predictor of non-small cell lung cancer outcome as it could contribute to identification of a subset of more aggressive tumours that progress to metastatic disease. Intriguingly, RASSF1A methylation has been reported as a good predictor of response to chemotherapy, whereby Fischer et al (2007) reported in the study of 92 NSCLC patients treated with gemcitabine that RASSF1A hypermethylation is a good predictor of overall survival, as those patients who demonstrated partial response to the administered chemotherapy and had tumours with hypermethylated RASSF1A 


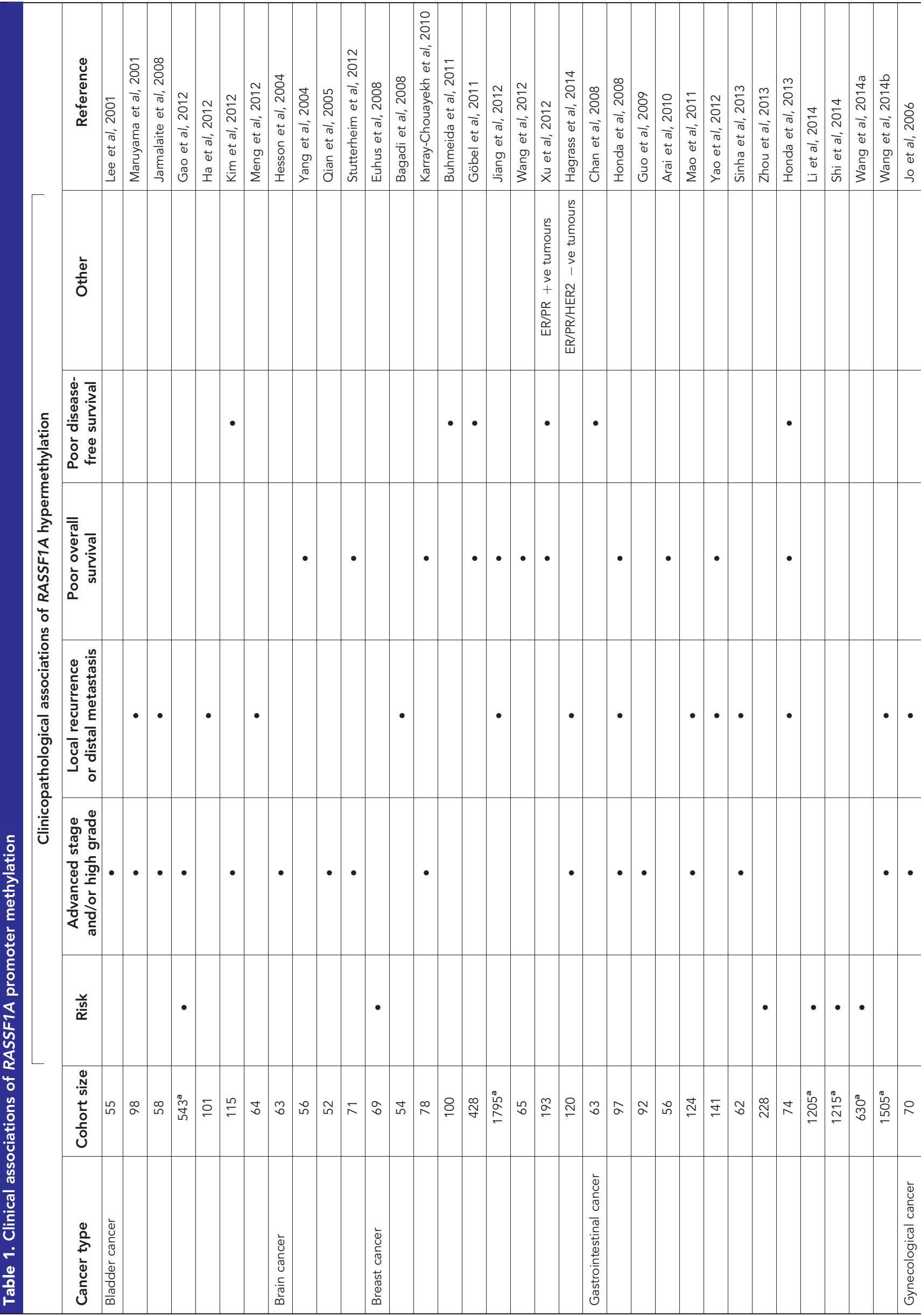




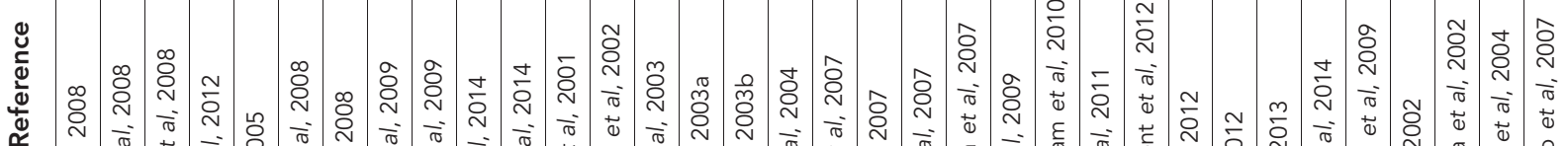

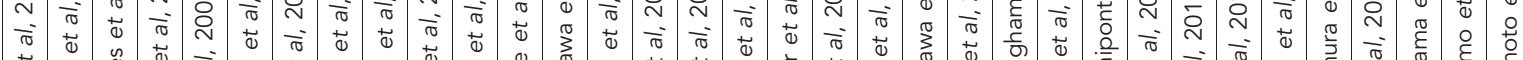

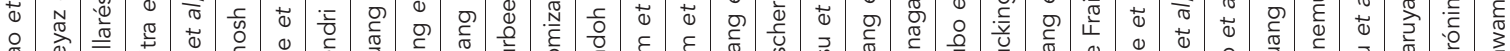 :}

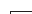

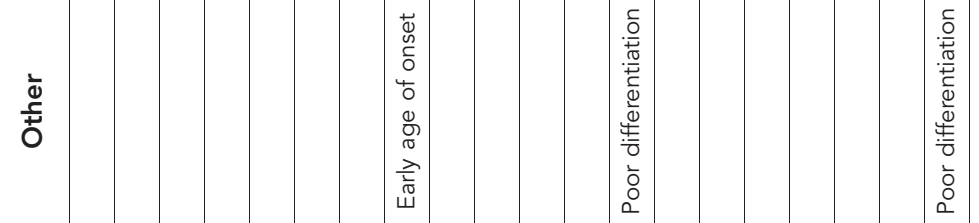

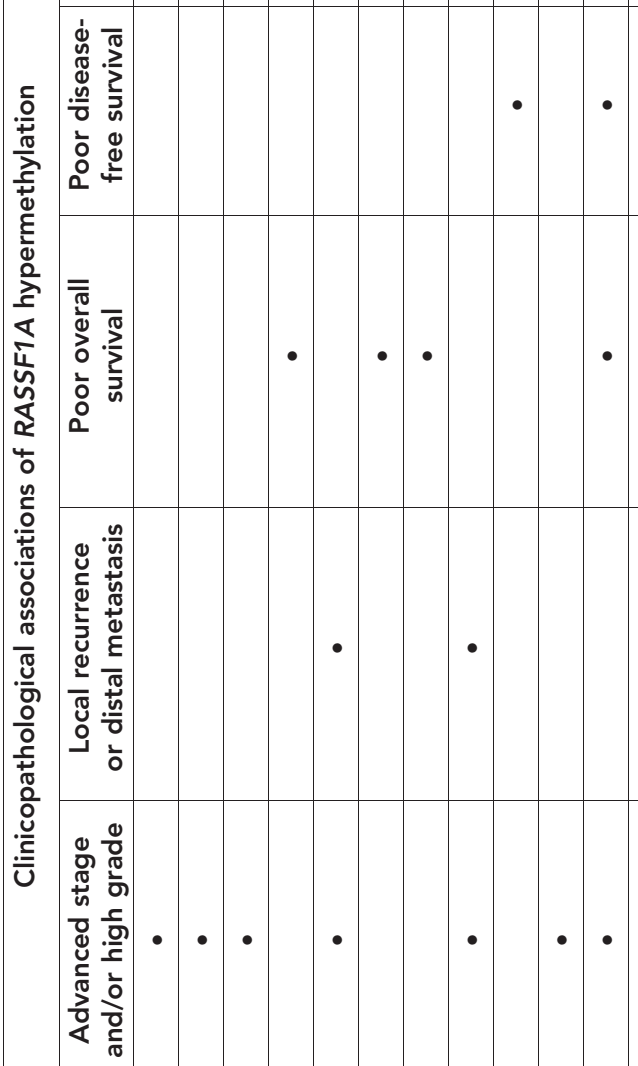

$\stackrel{\breve{m}}{\underline{\underline{M}}}$

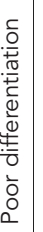

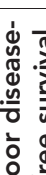




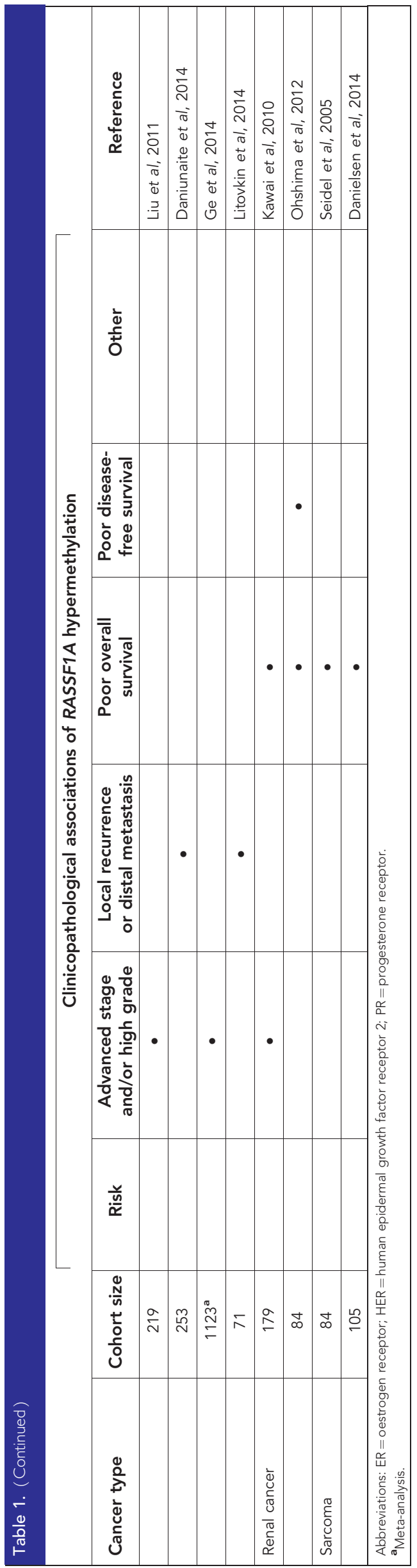

had significantly longer survival time. Additionally, De Fraipont et al (2012) in a study of 528 NSCLC patients treated with either gemcitabine or paclitaxel demonstrated significant differences in disease-free survival of patients whose tumours had methylated RASSF1A, whereby those patients who received paclitaxel chemotherapy had longer survival than those patients who were treated with gemcitabine. Altogether, the vast clinical evidence presented in lung cancer studies lends strong support to the clinical utility of RASSF1A methylation.

\section{GASTROINTESTINAL CANCER}

Correlation of RASSF1A methylation with cancer risk is best validated in gastrointestinal (GI) cancer. Zhou et al (2013) in a study of 112 oesophageal squamous cell carcinomas (ESCC), 116 gastric cardia adenocarcinomas (GCA) and 235 normal controls reported that RASSF1A promoter methylation associates with 5.9 OR of development of ESCC and 7.5 OR for GCA. This association has been recently corroborated in three different meta-analyses in 1205 liver (Li et al, 2014), 1215 gastric (Shi et al, 2014) and 630 colorectal (Wang et al, 2014a) tumours, indicating that RASSF1A methylation is strongly associated with the pathogenesis of GI cancer (Li et al, 2014; Shi et al, 2014; Wang et al, 2014a). Nonetheless, the role of epigenetic inactivation of RASSF1A does not restrict to the onset of GI malignancies. Honda et al (2008) in a study of 97 hepatoblastoma patients demonstrated that RASSF1A methylation is an independent predictor of outcome in both early- and advanced-stage patients, suggesting that RASSF1A inactivation associates with a more aggressive tumour phenotype. Altogether, four independent studies in liver cancer and one in gastric cancer demonstrated that RASSF1A hypermethylation is linked with poor disease-free (Chan et al, 2008; Honda et al, 2013) and overall survival (Honda et al, 2008; Arai et al, 2010; Yao et al, 2012). Furthermore, the liver and gastric malignancies with inactivated RASSF1A appear to have more clinicopathological characteristics that indicate more aggressive phenotype, such as advanced stage (Honda et al, 2008; Guo et al, 2009), lymph node involvement (Yao et al, 2012) and metastasis (Honda et al, 2008, 2013). There are no reports to date on the correlation of RASSF1A promoter methylation with the outcome of colorectal and oesophageal cancer; however, the body of evidence suggests that inactivation of RASSF1A, similar to liver and gastric lesions, is an adequate clinical marker of more invasive colorectal and oesophageal tumours with advanced stage, high grade, regional lymph involvement and distant metastases (Mao et al, 2011; Sinha et al, 2013; Wang et al, 2014b).

\section{OTHER CANCERS}

Association of RASSF1A hypermethylation with cancer risk, beyond breast, GI and lung malignancies, as discussed above, has been also described in bladder cancer (Gao et al, 2012). Gao et al (2012) in a meta-analysis of 543 cases and 217 controls pooled from 10 different studies reported an increased risk of bladder cancer with OR of 7.29 in tumours with hypermethylated RASSF1A. Further evidence to support RASSF1A hypermethylation as a marker of accelerated tumourogenesis comes from a study of 68 nasopharyngeal carcinomas by Fendri et al (2009), whereby the authors reported an early age of onset of those patients whose tumours had hypermethylated RASSF1A.

A strong association of RASSF1A with more invasive characteristics of tumours has been noted in prostate cancer, whereby tumours with RASSF1A promoter methylation associate with high Gleason and PSA scores, advanced stage in five independent studies (Liu et al, 2002, 2011; Maruyama et al, 2002; Jerónimo et al, 2004; 
Kawamoto et al, 2007) and in a meta-analysis of 1123 cases (Ge et al, 2014). Recently, higher risk of biochemical recurrence has also been described in association with RASSF1A hypermethylation in prostate cancer (Daniunaite et al, 2014; Litovkin et al, 2014).

RASSF1A methylation has been linked to advanced stage and high grade tumours of bladder (Lee et al, 2001; Maruyama et al, 2001; Jarmalaite et al, 2008; Gao et al, 2012; Kim et al, 2012), endometrium (Jo et al, 2006; Liao et al, 2008; Pallarés et al, 2008), cervix (Neyaz et al, 2008), head and neck (Li et al, 2005; Fendri et al, 2009; Yang et al, 2014; Zhang et al, 2014), melanoma (Tanemura et al, 2009), kidney (Kawai et al, 2010) and brain tumours, such as glioma (Hesson et al, 2004), neuroblastoma (Stutterheim et al, 2012) and pituitary adenomas (Qian et al, 2005). Some of these tumours with advanced stage or high grade and hypermethylated RASSF1A, such as bladder (Maruyama et al, 2001; Jarmalaite et al, 2008; Meng et al, 2012), endometrium (Jo et al, 2006) and head and neck (Li et al, 2005; Fendri et al, 2009) are also associated with local and distal metastases, whereas neuroblastomas (Yang et al, 2004; Stutterheim et al, 2012), bladder (Kim et al, 2012), head and neck (Ghosh et al, 2008; Lee et al, 2008; Zhang et al, 2014), kidney (Kawai et al, 2010; Ohshima et al, 2012) and cervical tumours (Mitra et al, 2012) associate with shorter overall survival. Additionally, RASSF1A hypermethylation as a prognostic marker of poor outcome has been also reported in sarcomas (Seidel et al, 2005; Danielsen et al, 2014). Together, these studies lend strong support to the use of RASSF1A hypermethylation as a prognostic biomarker of poor outcome and indicate that inactivation of RASSF1A has a key role in cancer progression. Indeed, studies in head and neck and renal cancers demonstrate that those tumours with high levels of RASSF1A methylation not only have poor outcome but progress to metastatic disease significantly faster than other tumours (Huang et al, 2009; Ohshima et al, 2012; Zhang et al, 2014).

\section{RASSF1A POLYMORPHIC VARIANT A133S}

Germ-line biomarkers, such as single-nucleotide polymorphisms (SNPs), similar to biomarkers derived from ctDNA are derived from stable and more readily accessible material and offer a promising clinical utility. Genetic screening using phenotypespecific SNP panels for retinal degradation has already been clinically validated and offers low-cost, high-quality molecular diagnoses (Katsanis and Katsanis, 2013). SNP of RASSF1A A133S alters the activity of RASSF1A and has been associated with increased risk of gastric cardia adenocarcinoma (Zhou et al, 2013), hepatocellular carcinoma (Bayram, 2012) lung adenocarcinoma (Kanzaki et al, 2006) early age of onset of breast cancer (Gao et al, 2008) and soft tissue sarcomas (Yee et al, 2012). Additionally, the polymorphic variant of RASSF1A negatively affects overall survival of soft tissue sarcomas (Yee et al, 2012) and accelerates progression of clear cell renal cell carcinoma (Kawai et al, 2012). Thus it is likely that inherited polymorphisms of RASSF1A could be used in combination with epigenetic inactivation of RASSF1A to better define patient populations at different risk of particular cancers.

\section{SUMMARY AND CONCLUSIONS}

Evidence for some of the noted clinical associations of RASSF1A methylation comes only from single cohort studies, and further investigation in large cohort studies is needed for validation. Additionally, clinical evidence on the impact of RASSF1A inactivation on risk and outcome of tumours with high frequency of RASSF1A methylation, such as pancreatic tumours, is lacking.
Nonetheless, association of RASSF1A promoter methylation with one or more clinicopathological characteristics has been validated in at least two independent studies for as many as 10 types of malignancies out of a total of 11 different cancer types that had been linked with RASSF1A promoter methylation (Table 2).

RASSF1A hypermethylation has been associated with cancer risk in a number of malignancies, suggesting its utility in monitoring premalignant tissues. However, existing evidence demonstrates that RASSF1A methylation status as a marker for cancer susceptibility is most likely to find its use in detection of earlystage GI and lung cancers (Table 2).

To explore the potential of RASSF1A hypermethylation as a candidate biomarker for aggressive tumours with poor outcome, we explored existing literature for any associations of RASSF1A epigenetic inactivation with clinical indicators of such phenotype, including poor overall survival and poor disease-free survival as well as advanced stage and/or grade and local recurrence and/or distal metastasis. Association of RASSF1A hypermethylation with adverse outcome has been substantiated in seven different types of malignancies, namely, brain, breast, GI, head and neck, lung and renal cancers and sarcomas (Table 2). The evidence is particularly strong in breast and lung cancers where as many as five independent reports in breast cancer cohorts and nine in lung cancer cohorts described RASSF1A hypermethylation as an independent predictor of cancer outcome. Additionally, high levels of RASSF1A methylation in breast, lung, GI and head and neck lesions has been also associated with shorter progression-free survival, suggesting that inactivation of RASSF1A has an important role in progression to the metastatic disease.

Advanced stage or high tumour grade, and particularly the presence of local and distant metastases at the time of diagnosis, are good indicators of the invasive potential of primary tumours. Indeed, associations with these indicators and inactivation of RASSF1A were reported in five out of the seven cancers where RASSF1A hypermethylation associated with adverse prognosis, with only three cancers lacking clear significant associations of RASSF1A hypermethylation with poor survival (Table 2).

The evidence discussed in this review gives strong support to the utility of RASSF1A promoter methylation as a biomarker for cancer risk as well as more invasive malignancies with poor outcome. Nonetheless, a number of reports in breast (Shinozaki et al, 2005; Cho et al, 2012), gynaecological (Pan et al, 2009; Montavon et al, 2012), GI (Kim et al, 2009; Okamoto et al, 2011) and lung (Safar et al, 2005; Chen et al, 2006; Brock et al, 2008; Niklinska, 2009) malignancies fail to identify any significant clinical association with RASSF1A promoter methylation. For instance, Niklinska et al (2009), in a study of 70 NSCLC patients did not find any associations of RASSF1A hypermethylation with overall survival. Similarly, advanced stage and lymph node metastases have been reported in GI malignancies (Table 1), including oesophageal cancer (Mao et al, 2011); however, Kim et al (2009) did not detect any significant association with RASSF1A hypermethylation in 50 oesophageal patients. Epigenetic inactivation of tumour-suppressor genes is a frequent event in human malignancies (Jones and Baylin, 2002). Indeed, methylation status of a number of other classic tumour-suppressor genes has been also extensively investigated, often in conjunction with RASSF1A gene methylation. Interestingly, in the above-mentioned study by Kim et al (2009), RASSF1A methylation was relatively low at $14 \%$, whereas the $A P C$ gene, with observed methylation frequency of $46 \%$, was identified as an independent predictor of outcome in the investigated cohort. Intriguingly, Safar et al (2005) in a study of clinical association with methylation status of a panel of 8 genes in the 105 NSCLC patients revealed that, although methylation of individual genes, including RASSF $1 A$, cannot be used as independent predictors of outcome, combined methylation status of RASSF1A, APC and ATM stratifies patients into groups with 


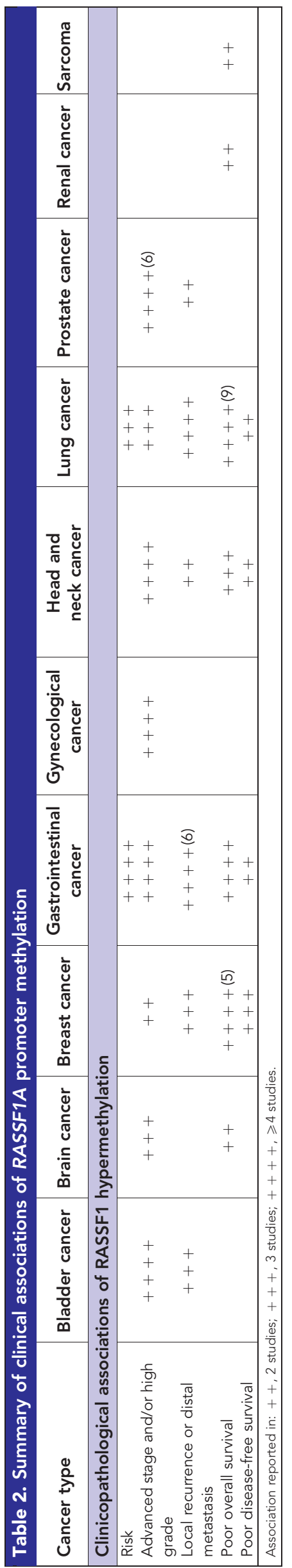

different clinical outcomes. Furthermore, the possibility exists that utility of RASSF1A methylation as an independent biomarker for cancer risk and outcome could be affected by Ras activation; evidence suggests that inactivation of RASSF1A is mutually exclusive with K-Ras mutation, where tumours with methylated RASSF1A had predominantly wt K-Ras (Dammann et al, 2003; Miranda et al, 2006; Cao et al, 2013). However, other reports demonstrate no correlation between RASSF1A inactivation and K-Ras mutation (Liu et al, 2007; Pijnenborg et al, 2007). More clinical studies are therefore needed to determine the association of Ras pathway deregulation with RASSF1A inactivation and its potential as a cancer biomarker.

Although it is possible that underlying differences in molecular composition and origin of malignancies might determine whether inactivation of RASSF1A can be a suitable predictor of clinical outcome, substantial variability exists in the definition of 'methylated' $v s$ 'non-methylated' calls, which may also affect the power and consistency. Variable methylation positivity of individual CG sites within relatively large CpG island locus of RASSF1A promoter and different methods used in many studies to assess DNA methylation status pose a significant hurdle that is likely to contribute to some inconsistency in the reported results.

In order to validate RASSF1A hypermethylation as an effective biomarker for cancer diagnostics, it is vital to clarify those $\mathrm{CpG}$ sites that contribute to the clinical phenotype across all tumour types. Given the substantial evidence outlined above, a definitive understanding of the true epigenetic signal at the RASSF1A promoter will undoubtedly improve the associations and be of great clinical benefit, potentially as the first broad pan-cancer biomarker of advanced disease. Altogether, the body of evidence suggests that epigenetic inactivation of the RASSF1A gene strongly associates with tumorigenesis and cancer risk and is a good candidate biomarker that could be utilised for diagnostic and therapeutic purposes.

\section{REFERENCES}

Arai Y, Honda S, Haruta M, Kasai F, Fujiwara Y, Ohshima J, Sasaki F, Nakagawara A, Horie H, Yamaoka H, Hiyama E, Kaneko Y (2010) Genome-wide analysis of allelic imbalances reveals $4 \mathrm{q}$ deletions as a poor prognostic factor and MDM4 amplification at 1q32.1 in hepatoblastoma. Genes Chromosomes Cancer 49: 596-609.

Avraham A, Uhlmann R, Shperber A, Birnbaum M, Sandbank J, Sella A, Sukumar S, Evron E (2012) Serum DNA methylation for monitoring response to neoadjuvant chemotherapy in breast cancer patients. Int $J$ Cancer 131: E1166-E1172.

Bagadi SAR, Prasad CP, Kaur J, Srivastava A, Prashad R, Gupta SD, Ralhan R (2008) Clinical significance of promoter hypermethylation of RASSF1A, RARbeta2, BRCA1 and HOXA5 in breast cancers of Indian patients. Life Sci 82: 1288-1292.

Bayram S (2012) RASSF1A Ala133Ser polymorphism is associated with increased susceptibility to hepatocellular carcinoma in a Turkish population. Gene 498: 264-269.

Brock MV, Hooker CM, Ota-Machida E, Han Y, Guo M, Ames S, Glöckner S, Piantadosi S, Gabrielson E, Pridham G, Pelosky K, Belinsky Sa, Yang SC, Baylin SB, Herman JG (2008) DNA methylation markers and early recurrence in stage I lung cancer. $N$ Engl J Med 358: 1118-1128.

Buckingham L, Penfield Faber L, Kim A, Liptay M, Barger C, Basu S, Fidler M, Walters K, Bonomi P, Coon J (2010) PTEN, RASSF1 and DAPK sitespecific hypermethylation and outcome in surgically treated stage I and II nonsmall cell lung cancer patients. Int J Cancer 126: 1630-1639.

Buhmeida A, Merdad A, El-Maghrabi J, Al-Thobaiti F, Ata M, Bugis A, Syrjänen K, Abuzenadah A, Chaudhary A, Gari M, Al-Qahtani M, Dallol A (2011) RASSF1A methylation is predictive of poor prognosis in female breast cancer in a background of overall low methylation frequency. Anticancer Res 31: 2975-2981.

Burbee DG, Forgacs E, Zochbauer-Muller S, Shivakumar L, Fong K, Gao B, Randle D, Kondo M, Virmani A, Bader S, Sekido Y, Latif F, Milchgrub S, Toyooka S, Gazdar AF, Lerman MI, Zabarovsky E, White M, Minna JD 
(2001) Epigenetic inactivation of RASSF1A in lung and breast cancers and malignant phenotype suppression. J Natl Cancer Inst 93: 691-699.

Cao D, Chen Y, Tang Y, Peng XC, Dong H, Li LH, Cheng K, Ge J, Liu JY (2013) Loss of RASSF1A expression in colorectal cancer and its association with k-ras status. Biomed Res Int 2013: 1-8.

Chan K, Lai P, Mok T, Chan HL, Ding C, Yeung SW, Lo YM (2008) Quantitative analysis of circulating methylated DNA as a biomarker for hepatocellular carcinoma. Clin Chem 54: 1528-1536.

Chen H, Suzuki M, Nakamura Y, Ohira M, Ando S, Iida T, Nakajima T, Nakagawara A, Kimura H (2006) Aberrant methylation of RASGRF2 and RASSF1A in human non-small cell lung cancer. Oncol Rep 15: 1281-1285.

Cho YH, Shen J, Gammon MD, Zhang Y-J, Wang Q, Gonzalez K, Xu X, Bradshaw PT, Teitelbaum SL, Garbowski G, Hibshoosh H, Neugut AI, Chen J, Santella RM (2012) Prognostic significance of gene-specific promoter hypermethylation in breast cancer patients. Breast Cancer Res Treat 131: 197-205.

Dammann R, Li C, Yoon JH, Chin PL, Bates S, Pfeifer GP (2000) Epigenetic inactivation of a RAS association domain family protein from the lung tumour suppressor locus 3p21.3. Nat Genet 25: 315-319.

Dammann R, Schagdarsurengin U, Liu L, Otto N, Gimm O, Dralle H, Boehm BO, Pfeifer GP, Hoang-Vu C (2003) Frequent RASSF1A promoter hypermethylation and K-ras mutations in pancreatic carcinoma. Oncogene 22: 3806-3812.

Danielsen SA, Lind GE, Kolberg M, Høland M, Bjerkehagen B, Sundby Hall K, van den Berg E, Mertens F, Smeland S, Picci P, Lothe RA (2014) Methylated RASSF1A in malignant peripheral nerve sheath tumors identifies neurofibromatosis type 1 patients with inferior prognosis. Neuro Oncol 17(1): 63-69.

Daniunaite K, Jarmalaite S, Kalinauskaite N, Petroska D, Laurinavicius A, Lazutka JR, Jankevicius F (2014) Prognostic value of RASSF1 promoter methylation in prostate cancer. J Urol 192(6): 1849-1855.

De Fraipont F, Levallet G, Creveuil C, Bergot E, Beau-Faller M, Mounawar M, Richard N, Antoine M, Rouquette I, Favrot MC, Debieuvre D, Braun D, Westeel V, Quoix E, Brambilla E, Hainaut P, Moro-Sibilot D, Morin F, Milleron B, Zalcman G (2012) An apoptosis methylation prognostic signature for early lung cancer in the IFCT-0002 trial. Clin Cancer Res 18: 2976-2986.

Donninger H, Vos M, Clark G (2007) The RASSF1A tumor suppressor. J Cell Sci 120(Pt 18): 3163-3172.

Endoh H, Yatabe Y, Shimizu S, Tajima K, Kuwano H, Takahashi T, Mitsudomi T (2003) RASSF1A gene inactivation in non-small cell lung cancer and its clinical implication. Int J Cancer 106: 45-51.

Euhus DM, Bu D, Milchgrub S, Xie X-J, Bian A, Leitch AM, Lewis CM (2008) DNA methylation in benign breast epithelium in relation to age and breast cancer risk. Cancer Epidemiol Biomarkers Prev 17: 1051-1059.

Fendri A, Masmoudi A, Khabir A, Sellami-Boudawara T, Daoud J, Frikha M, Ghorbel A, Gargouri A, Mokdad-Gargouri R (2009) Inactivation of RASSF1A, RAR $\beta 2$ and DAP-kinase by promoter methylation cosrrelates with lymph node metastasis in nasopharyngeal carcinoma. Cancer Biol $\mathbf{8}$ 444-451.

Fiegl H, Millinger S, Mueller-holzner E, Marth C, Ensinger C, Berger A, Klocker H, Goebel G, Widschwendter M (2005) Circulating tumorspecific DNA: a marker for monitoring efficacy of adjuvant therapy in cancer patients. Cancer Res (2005) 65(4): 1141-1145.

Fischer JR, Ohnmacht U, Rieger N, Zemaitis M, Stoffregen C, Manegold C, Lahm H (2007) Prognostic significance of RASSF1A promoter methylation on survival of non-small cell lung cancer patients treated with gemcitabine. Lung Cancer 56: 115-123.

Gao B, Xie X, Huang C, Shames D, Chen T, Lewis C, Bian A, Zhang B, Olopade O, Garber J, Euhus D, Tomlinson G, Minna J (2008) RASSF1A polymorphism $\mathrm{A} 133 \mathrm{~S}$ is associated with early onset breast cancer in BRCA1/2 mutation carriers. Cancer Res 68(1): 22-25.

Gao T, Wang S, He B, Pan Y, Song G, Gu L, Chen L, Nie Z, Xu Y, Li R (2012) The association of RAS association domain family Protein1A (RASSF1A) methylation states and bladder cancer risk: a systematic review and metaanalysis. PLoS One 7: e48300.

Ge Y-Z, Xu L-W, Jia R-P, Xu Z, Feng Y-M, Wu R, Yu P, Zhao Y, Gui Z-L, Tan S-J, Song Q (2014) The association between RASSF1A promoter methylation and prostate cancer: evidence from 19 published studies. Tumour Biol 35: 3881-3890.

Ghosh S, Ghosh A, Maiti GP, Alam N, Roy A, Roy B, Roychoudhury S, Panda CK (2008) Alterations of 3p21.31 tumor suppressor genes in head and neck squamous cell carcinoma: correlation with progression and prognosis. Int J Cancer 123: 2594-2604.

Göbel G, Auer D, Gaugg I, Schneitter A, Lesche R, Müller-Holzner E, Marth C, Daxenbichler G (2011) Prognostic significance of methylated RASSF1A and PITX2 genes in blood- and bone marrow plasma of breast cancer patients. Breast Cancer Res Treat 130: 109-117.

Guo C, Tommasi S, Liu L, Yee JK, Dammann R, Pfeifer GP (2007) RASSF1A is part of a complex similar to the Drosophila Hippo/Salvador/Lats Tumor-Suppressor Network. Curr Biol 17: 700-705.

Guo W, Dong Z, Chen Z, Yang Z, Wen D, Kuang G, Guo Y, Shan B (2009) Aberrant CpG island hypermethylation of RASSF1A in gastric cardia adenocarcinoma. Cancer Invest 27: 459-465.

Ha YS, Jeong P, Kim JS, Kwon WA, Kim IY, Yun SJ, Kim GY, Choi YH, Moon SK, Kim W (2012) Tumorigenic and prognostic significance of RASSF1A expression in low-grade (WHO grade 1 and grade 2) nonmuscle-invasive bladder cancer. Urology 79: 1411.e1-e6.

Hagrass Ha, Pasha HF, Shaheen MA, Abdel Bary EH, Kassem R (2014) Methylation status and protein expression of RASSF1A in breast cancer patients. Mol Biol Rep 41: 57-65.

Hesson L, Bièche I, Krex D, Criniere E, Hoang-Xuan K, Maher ER, Latif F (2004) Frequent epigenetic inactivation of RASSF1A and BLU genes located within the critical 3p21.3 region in gliomas. Oncogene 23: 2408-2419.

Hesson LB, Cooper WN, Latif F (2007) The role of RASSF1A methylation in cancer. Dis Markers 23: 73-87.

Honda S, Haruta M, Sugawara W, Sasaki F, Ohira M, Matsunaga T, Yamaoka H, Horie H, Ohnuma N, Nakagawara A, Hiyama E, Todo S, Kaneko Y (2008) The methylation status of RASSF1A promoter predicts responsiveness to chemotherapy and eventual cure in hepatoblastoma patients. Int J Cancer 123: $1117-1125$.

Honda S, Miyagi H, Suzuki H, Minato M, Haruta M, Kaneko Y, Hatanaka KC, Hiyama E, Kamijo T, Okada T, Taketomi A (2013) RASSF1A methylation indicates a poor prognosis in hepatoblastoma patients. Pediatr Surg Int 29: $1147-1152$.

Hsu H-S, Chen T-P, Hung C-H, Wen C-K, Lin R-K, Lee H-C, Wang Y-C (2007) Characterization of a multiple epigenetic marker panel for lung cancer detection and risk assessment in plasma. Cancer 110: 2019-2026.

Huang K, Huang S, Chen I, Liao C, Wang H, Hsieh L (2009) Methylation of RASSF1A, RASSF2A, and HIN-1 is associated with poor outcome after radiotherapy, but not surgery, in oral squamous cell carcinoma. Clin Cancer 15: 4174-4180.

Huang Y, Wu W, Wu K, Xu X, Tang W (2014) Association of RASSF1A promoter methylation with lung cancer risk: a meta-analysis. Asian Pac $J$ Cancer Prev 15: 10325-10328.

Jarmalaite S, Jankevicius F, Kurgonaite K, Suziedelis K, Mutanen P, HusgafvelPursiainen K (2008) Promoter hypermethylation in tumour suppressor genes shows association with stage, grade and invasiveness of bladder cancer. Oncology 75: 145-151.

Jerónimo C, Henrique R, Hoque M, Mambo E, Ribeiro FR, Varzim G, Oliveira J, Teixeira MR, Lopes C, Sidransky D (2004) A quantitative promoter methylation profile of prostate cancer. Clin Cancer 10: 8472-8478.

Jiang Y, Cui L, Chen W, Shen S, Ding L (2012) The prognostic role of RASSF1A promoter methylation in breast cancer: a meta-analysis of published data. PLoS One 7: e36780.

Jo H, Kim J, Kang G, Park N, Song Y, Kang S, Lee H (2006) Association of promoter hypermethylation of the RASSF1A gene with prognostic parameters in endometrial cancer. Clin Cancer Res 16: 205-209.

Jones PA, Baylin SB (2002) The fundamental role of epigenetic events in cancer. Nat Rev Genet 3: 415-428.

Kanzaki H, Hanafusa H, Yamamoto H (2006) Single nucleotide polymorphism at codon 133 of the RASSF1 gene is preferentially associated with human lung adenocarcinoma risk. Cancer Lett 238: 128-134.

Karray-Chouayekh S, Trifa F, Khabir A, Boujelbane N, Sellami-Boudawara T, Daoud J, Frikha M, Jlidi R, Gargouri A, Mokdad-Gargouri R (2010) Aberrant methylation of RASSF1A is associated with poor survival in Tunisian breast cancer patients. J Cancer Res Clin Oncol 136: 203-210.

Katsanis SH, Katsanis N (2013) Molecular genetic testing and the future of clinical genomics. Nat Rev Genet 14: 415-426.

Kawai Y, Sakano S, Okayama N, Suehiro Y, Matsuyama H, Hinoda Y (2012) Association of RASSF1A genotype and haplotype with the progression of clear cell renal cell carcinoma in Japanese patients. BJU Int 110: 1070-1075.

Kawai Y, Sakano S, Suehiro Y, Okada T, Korenaga Y, Hara T, Naito K, Matsuyama H, Hinoda Y (2010) Methylation level of the RASSF1A 
promoter is an independent prognostic factor for clear-cell renal cell carcinoma. Ann Oncol 21: 1612-1617.

Kawamoto K, Okino ST, Place RF, Urakami S, Hirata H, Kikuno N, Kawakami T, Tanaka Y, Pookot D, Chen Z, Majid S, Enokida H, Nakagawa M, Dahiya R (2007) Epigenetic modifications of RASSF1A gene through chromatin remodeling in prostate cancer. Clin Cancer Res 13: 2541-2548.

Kim D, Kim J, Ji Y, Shim Y, Kim H, Han J, Park J (2003a) Hypermethylation of RASSF1A promoter is associated with the age at starting smoking and a poor prognosis in primary non-small cell lung cancer. Cancer Res 63 : 3743-3746.

Kim D, Kim J, Park J, Lee S, Ji Y, Kwon Y, Shim Y, Han J, Park J (2003b) Relationship of Ras association domain family 1 methylation and K-ras mutation in primary non-small cell lung cancer. Cancer Res 63: 6206-6211.

Kim JS, Chae Y, Ha Y-S, Kim IY, Byun SS, Yun S-J, Kim W-J (2012) Ras association domain family $1 \mathrm{~A}$ : a promising prognostic marker in recurrent nonmuscle invasive bladder cancer. Clin Genitourin Cancer 10: 114-120.

Kim YT, Park J-Y, Jeon YK, Park SJ, Song JY, Kang CH, Sung SW, Kim JH (2009) Aberrant promoter CpG island hypermethylation of the adenomatosis polyposis coli gene can serve as a good prognostic factor by affecting lymph node metastasis in squamous cell carcinoma of the esophagus. Dis Esophagus 22: 143-150.

Ko E, Lee B, Bin, Kim Y, Lee EJ, Cho EY, Han J, Shim YM, Park J, Kim D-H (2013) Association of RASSF1A and p63 with poor recurrence-free survival in node-negative stage I-II non-small cell lung cancer. Clin Cancer Res 19: 1204-1212.

Kok K, Osinga J, Carritt B, Davis MB, van der Hout AH, van der Veen AY, Landsvater RM, de Leij LF, Berendsen HH, Postmus PE (1987) Deletion of a DNA sequence at the chromosomal region 3p21 in all major types of lung cancer. Nature 330: 578-581.

Kubo T, Yamamoto H, Ichimura K, Jida M, Hayashi T, Otani H, Tsukuda K, Sano Y, Kiura K, Toyooka S (2009) DNA methylation in small lung adenocarcinoma with bronchioloalveolar carcinoma components. Lung Cancer 65: 328-332.

Lee E-S, Issa J-P, Roberts DB, Williams MD, Weber RS, Kies MS, El-Naggar AK (2008) Quantitative promoter hypermethylation analysis of cancer-related genes in salivary gland carcinomas: comparison with methylation-specific PCR technique and clinical significance. Clin Cancer Res 14: 2664-2672.

Lee M, Kim H, Byun D, Lee S, Lee C, Kim J, Chang S, Chi S (2001) Frequent epigenetic inactivation of RASSF1A in human bladder carcinoma. Cancer Res 61: 6688-6692.

Lee SM, Lee WK, Kim DS, Park JY (2012) Quantitative promoter hypermethylation analysis of RASSF1A in lung cancer: comparison with methylation-specific PCR technique and clinical significance. Mol Med Rep 5: 239-244.

Li J, El-Naggar A, Mao L (2005) Promoter methylation of p16INK4a, RASSF1A, and DAPK is frequent in salivary adenoid cystic carcinoma. Cancer 104: 771-776.

Li W, Deng J, Jiang P, Zeng X, Hu S, Tang J (2012) Methylation of the RASSF1A and RAR $\beta$ genes as a candidate biomarker for lung cancer. Exp Ther Med 3: 1067-1071.

Li Y-S, Xie Q, Yang D-Y, Zheng Y (2014) Role of RASSF1A promoter methylation in the pathogenesis of hepatocellular carcinoma: a metaanalysis of 21 cohort studies. Mol Biol Rep 41: 3925-3933.

Liao X, Siu MK-Y, Chan KY-K, Wong ES-Y, Ngan HY-S, Chan QK-Y, Li AS-M, Khoo U-S, Cheung AN-Y (2008) Hypermethylation of RAS effector related genes and DNA methyltransferase 1 expression in endometrial carcinogenesis. Int J Cancer 123: 296-302.

Litovkin K, Joniau S, Lerut E, Laenen A, Gevaert O, Spahn M, Kneitz B, Isebaert S, Haustermans K, Beullens M, Van Eynde A, Bollen M (2014) Methylation of PITX2, HOXD3, RASSF1 and TDRD1 predicts biochemical recurrence in high-risk prostate cancer. J Cancer Res Clin Oncol 140(11): 1849-1861.

Liu L, Kron KJ, Pethe VV, Demetrashvili N, Nesbitt ME, Trachtenberg J, Ozcelik H, Fleshner NE, Briollais L, van der Kwast TH, Bapat B (2011) Association of tissue promoter methylation levels of APC, TGF $\beta 2$, HOXD3 and RASSF1A with prostate cancer progression. Int J Cancer 129: 2454-2462.

Liu L, Yoon J-H, Dammann R, Pfeifer GP (2002) Frequent hypermethylation of the RASSF1A gene in prostate cancer. Oncogene 21: 6835-6840.

Liu Y, Gao W, Siegfried JM, Weissfeld JL, Luketich JD, Keohavong P (2007) Promoter methylation of RASSF1A and DAPK and mutations of K-ras, p53, and EGFR in lung tumors from smokers and never-smokers. BMC Cancer 7: 74.
Mao W, Li P, Zheng Q, Wang C, Ge M, Hu F, Fang X, Dong Z, Ling Z (2011) Hypermethylation-modulated downregulation of RASSF1A expression is associated with the progression of esophageal cancer. Arch Med Res 42: $182-188$.

Maruyama R, Toyooka S, Toyooka K, Harada K, Virmani S, ZöchbauerMüller S, Farinas A, Vakar-Lopes F, Minna J, Sagalowsky A, Czerniak B, Gazdar A (2001) Aberrant promoter methylation profile of bladder cancer and its relationship to clinicopathological features. Cancer Res $\mathbf{6 1}$ : 8659-8663.

Maruyama R, Toyooka S, Toyooka K, Virmani A, Zöchbauer-Müller S, Farinas A, Minna J, McConnell J, Frenkel E, Gazdar A (2002) Aberrant promoter methylation profile of prostate cancers and its relationship to clinicopathological features. Clin Cancer 8: 514-519.

Mehlen P, Puisieux A (2006) Metastasis: a question of life or death. Nat Rev Cancer 6: 449-458.

Meng W, Huebner A, Shabsigh A, Chakravarti A, Lautenschlaeger T (2012) Combined RASSF1A and RASSF2A promoter methylation analysis as diagnostic biomarker for bladder cancer. Mol Biol Int 2012: 701814.

Miranda E, Destro A, Malesci A, Balladore E, Bianchi P, Baryshnikova E, Franchi G, Morenghi E, Laghi L, Gennari L, Roncalli M (2006) Genetic and epigenetic changes in primary metastatic and nonmetastatic colorectal cancer. Br J Cancer 95: 1101-1107.

Mitra S, Mazumder Indra D, Basu PS, Mondal RK, Roy A, Roychoudhury S, Panda CK (2012) Alterations of RASSF1A in premalignant cervical lesions: clinical and prognostic significance. Mol Carcinog 51: 723-733.

Montavon C, Gloss BS, Warton K, Barton Ca, Statham AL, Scurry JP, Tabor B, Nguyen TV, Qu W, Samimi G, Hacker NF, Sutherland RL, Clark SJ, O'Brien PM (2012) Prognostic and diagnostic significance of DNA methylation patterns in high grade serous ovarian cancer. Gynecol Oncol 124: $582-588$

Neyaz MK, Kumar RS, Hussain S, Naqvi SH, Kohaar I, Thakur N, Kashyap V, Das BC, Husain SA, Bharadwaj M (2008) Effect of aberrant promoter methylation of FHIT and RASSF1A genes on susceptibility to cervical cancer in a North Indian population. Biomarkers 13: 597-606.

Niklinska W (2009) Prognostic significance of DAPK and RASSF1A promoter hypermethylation in non-small cell lung cancer (NSCLC). Folia Histochem Cytobiol 47: 47-48.

Ohshima J, Haruta M, Fujiwara Y, Watanabe N, Arai Y, Ariga T, Okita H, Koshinaga T, Oue T, Hinotsu S, Nakadate H, Horie H, Fukuzawa M, Kaneko Y (2012) Methylation of the RASSF1A promoter is predictive of poor outcome among patients with Wilms tumor. Pediatr Blood Cancer 59: 499-505.

Okamoto Y, Sawaki A, Ito S, Nishida T, Takahashi T, Toyota M, Suzuki H, Shinomura Y, Takeuchi I, Shinjo K, An B, Ito H, Yamao K, Fuiji M, Murakami H, Osada H, Kataoka H, Joh T, Sekido Y, Kondo Y (2011) Aberrant DNA methylation associated with aggressiveness of gastrointestinal stromal tumour. Gut 61: 392-401.

Pallarés J, Velasco A, Eritja N, Santacana M, Dolcet X, Cuatrecasas M, Palomar-Asenjo V, Catasús L, Prat J, Matias-Guiu X (2008) Promoter hypermethylation and reduced expression of RASSF1A are frequent molecular alterations of endometrial carcinoma. Mod Pathol 21: 691-699.

Pan Z, Li J, Pan X, Chen S, Wang Z, Li F, Qu S, Shao R (2009) Methylation of the RASSF1A gene promoter in Uigur women with cervical squamous cell carcinoma. Tumori 95: 76-80.

Pijnenborg JMa, Dam-de Veen GC, Kisters N, Delvoux B, van Engeland M, Herman JG, Groothuis PG (2007) RASSF1A methylation and K-ras and B-raf mutations and recurrent endometrial cancer. Ann Oncol 18: 491-497.

Ponomaryova Aa, Rykova EY, Cherdyntseva NV, Skvortsova TE, Dobrodeev AY, Zav'yalov Aa, Bryzgalov LO, Tuzikov Sa, Vlassov VV, Laktionov PP (2013) Potentialities of aberrantly methylated circulating DNA for diagnostics and post-treatment follow-up of lung cancer patients. Lung Cancer 81: 397-403.

Qian ZR, Sano T, Yoshimoto K, Yamada S, Ishizuka A, Mizusawa N, Horiguchi H, Hirokawa M, Asa SL (2005) Inactivation of RASSF1A tumor suppressor gene by aberrant promoter hypermethylation in human pituitary adenomas. Lab Invest 85: 464-473.

Reis-Filho JS, Pusztai L (2011) Gene expression profiling in breast cancer: classification, prognostication, and prediction. Lancet 378: 1812-1823.

Safar A, Spencer H, Su X, Coffey M, Cooney C, Ratnasinghe L, Hutchins L, Fan C (2005) Methylation profiling of archived non-small cell lung cancer: a promising prognostic system. Clin Cancer Res 11: 4400-4405.

Seidel C, Bartel F, Rastetter M, Bluemke K, Wurl P, Taubert H, Dammann R (2005) Alterations of cancer-related genes in soft tissue sarcomas: 
hypermethylation of RASSF1A is frequently detected in leiomyosarcoma and associated with poor prognosis in sarcoma. Int J Cancer 114: 442-447.

Shi D-T, Han M, Gao N, Tian W, Chen W (2014) Association of RASSF1A promoter methylation with gastric cancer risk: a meta-analysis. Tumour Biol 35: 943-948.

Shinozaki M, Hoon D, Giuliano A, Hansen N, Wang H, Turner R, Taback B (2005) Distinct hypermethylation profile of primary breast cancer is associated with sentinel lymph node metastasis. Clin Cancer Res 11: 2156-2162.

Sinha R, Hussain S, Mehrotra R, Kumar RS, Kumar K, Pande P, Doval DC, Basir SF, Bharadwaj M (2013) Kras gene mutation and RASSF1A, FHIT and MGMT gene promoter hypermethylation: indicators of tumor staging and metastasis in adenocarcinomatous sporadic colorectal cancer in Indian population. PLoS One 8: e60142.

Stuopelyte K, Daniūnaitė K, Laurinavičienė A, Ostapenko V, Jarmalaite S (2013) High-resolution melting-based quantitative analysis of RASSF1 methylation in breast cancer. Medicina (Kaunas) 49: 78-83.

Stutterheim J, Ichou FA, den Ouden E, Versteeg R, Caron HN, Tytgat GaM, van der Schoot CE (2012) Methylated RASSFla is the first specific DNA marker for minimal residual disease testing in neuroblastoma. Clin Cancer Res 18: $808-814$

Tanemura A, Terando A, Sim M, van Hoesel A, de Maat M, Morton D, Hoon D (2009) CpG island methylator phenotype predicts progression of malignant melanoma. Clin Cancer Res 15: 1801-1807.

Tomizawa Y, Kohno T, Kondo H, Otsuka A, Nishioka M, Niki T, Yamada T, Maeshima A, Yoshimura K, Saito R, Minna J, Yokota J (2002) Clinicopathological significance of epigenetic inactivation of RASSF1A at 3p21.3 in stage I lung adenocarcinoma. Clin Cancer 8: 2362-2368.

Van der Weyden L, Adams DJ (2007) The Ras-association domain family (RASSF) members and their role in human tumourigenesis. Biochim Biophys Acta 1776: 58-85.

Wang H-L, Liu P, Zhou P-Y, Zhang Y (2014a) Promoter methylation of the RASSF1A gene may contribute to colorectal cancer susceptibility: a metaanalysis of cohort studies. Ann Hum Genet 78: 208-216.

Wang H-L, Zhang Y, Liu P, Zhou P-Y (2014b) Aberrant promoter methylation of RASSF1A gene may be correlated with colorectal carcinogenesis: a meta-analysis. Mol Biol Rep 41: 3991-3999.

Wang J, Lee J, Wang L, Liu D, Lu C (2004) Value of p16 INK4a and RASSF1A promoter hypermethylation in prognosis of patients with resectable nonsmall cell lung cancer. Clin Cancer 6119-6125.

Wang J, Wang B, Chen X, Bi J (2011) The prognostic value of RASSF1A promoter hypermethylation in non-small cell lung carcinoma: a systematic review and meta-analysis. Carcinogenesis 32: 411-416.
Wang S, Dorsey TH, Terunuma A, Kittles Ra, Ambs S, Kwabi-Addo B (2012) Relationship between tumor DNA methylation status and patient characteristics in African-American and European-American women with breast cancer. PLoS One 7: e37928.

Wang Y, Yu Z, Wang T, Zhang J, Hong L, Chen L (2007) Identification of epigenetic aberrant promoter methylation of RASSF1A in serum DNA and its clinicopathological significance in lung cancer. Lung Cancer 56: 289-294.

Xu J, Shetty PB, Feng W, Chenault C, Bast Jr RC, Issa JJ, Hilsenbeck SG, Yu Y (2012) Methylation of HIN-1, RASSF1A, RIL and CDH13 in breast cancer is associated with clinical characteristics, but only RASSF1A methylation is associated with outcome. BMC Cancer 12: 243.

Yanagawa N, Tamura G, Oizumi H, Kanauchi N, Endoh M, Sadahiro M, Motoyama T (2007) Promoter hypermethylation of RASSF1A and RUNX3 genes as an independent prognostic prediction marker in surgically resected non-small cell lung cancers. Lung Cancer 58: 131-138.

Yang Q, Zage P, Kagan D, Tian Y, Seshadri R, Salwen H, Liu S, Chlenski A, Cohn S (2004) Association of epigenetic inactivation of RASSF1A with poor outcome in human neuroblastoma. Clin Cancer Res 10: 8493-8500.

Yang X, Dai W, Kwong DL-W, Szeto CYY, Wong EH-W, Ng WT, Lee AWM, Ngan RKC, Yau CC, Tung SY, Lung ML (2014) Epigenetic markers for noninvasive early detection of nasopharyngeal carcinoma by methylationsensitive high resolution melting. Int J Cancer 136(4): E127-E135.

Yao D, Shi J, Shi B, Wang N, Liu W, Zhang G, Ji M, Xu L, He N, Hou P (2012) Quantitative assessment of gene methylation and their impact on clinical outcome in gastric cancer. Clin Chim Acta 413: 787-794.

Yee KS, Grochola L, Hamilton G, Grawenda A, Bond EE, Taubert H, Wurl P, Bond GL, O'Neill E (2012) A RASSF1A polymorphism restricts p53/p73 activation and associates with poor survival and accelerated age of onset of soft tissue sarcoma. Cancer Res 72: 2206-2217.

Zhang C-Y, Zhao Y-X, Xia R-H, Han J, Wang B-S, Tian Z, Wang L-Z, Hu Y-H, Li J (2014) RASSF1A promoter hypermethylation is a strong biomarker of poor survival in patients with salivary adenoid cystic carcinoma in a Chinese population. PLoS One 9: e110159.

Zhou SL, Cui J, Fan ZM, Li XM, Li JL, Liu BC, Zhang DY, Liu HY, Zhao XK, Song X, Wang R, Yan ZC, Yi HX, Wang LD (2013) Polymorphism of $\mathrm{A} 133 \mathrm{~S}$ and promoter hypermethylation in Ras association domain family 1A gene (RASSF1A) is associated with risk of esophageal and gastric cardia cancers in Chinese population from high incidence area in northern China. BMC Cancer 13: 259. 